\title{
Decolorization of Synthetic Azo Dyes under Anaerobic Condition in a Continuous Stirred Tank Reactor
}

\author{
Mohamad Adib Syahmi Latif ${ }^{1}$ (D) Fazilah Ariffin $^{1,2 *}(\mathbb{D})$, Rudiyanto ${ }^{3}$ (D) , Shahrul \\ Ismail $^{4}$ (D) , Noorazrimi Umor ${ }^{5}$ iD , Abu Zahrim Yaser ${ }^{6}$ (D) and Zaharah Ibrahim ${ }^{7}$ \\ ${ }^{1}$ Faculty of Science and Marine Environment, Universiti Malaysia Terengganu, 21030 Kuala Nerus, \\ Terengganu, Malaysia. \\ ${ }^{2}$ Biological Security and Sustainability Research Group, Universiti Malaysia Terengganu, \\ 21030 Kuala Nerus, Terengganu, Malaysia. \\ ${ }^{3}$ Faculty of Fisheries and Food Science, Universiti Malaysia Terengganu, 21030 Kuala Nerus, \\ Terengganu, Malaysia. \\ ${ }^{4}$ Faculty of Ocean Engineering Technology and Informatics, Universiti Malaysia Terengganu, \\ 21030 Kuala Nerus, Terengganu, Malaysia. \\ ${ }^{5}$ Department of Microbiology, Faculty of Applied Science, Universiti Teknologi MARA Negeri Sembilan Branch, \\ Kuala Pilah Campus, 72000 Kuala Pilah, Negeri Sembilan, Malaysia. \\ ${ }^{6}$ Faculty of Engineering, Universiti Malaysia Sabah, Jalan UMS, 88400 Kota Kinabalu, Sabah, Malaysia. \\ ${ }^{7}$ Faculty of Science, Universiti Teknologi Malaysia, 81310, UTM Johor Bahru, Johor, Malaysia.
}

\begin{abstract}
Biological treatment for textile wastewater always has a limitation in term of time of reaction and uncertainty along the process. This study focused on the decolorization of synthetic azo dyes in batch reactors with controlled thermotolerant anaerobic conditions. Less-volatile digested sludge collected from a palm oil biogas reactor was used as the organic biodegradation agent for azo dyes. Digested sludge contains high amounts of microbes with uncertain species viable for decolorization purposes. Sodium acetate trihydrate $\left(\mathrm{C}_{2} \mathrm{H}_{9} \mathrm{NaO}_{5}\right)$ was used as carbon source and mixed with a specific composition of minimum salt media (MSM) in batch reactors as an additional nutrient. Digested sludge both in mesophilic $\left(35^{\circ} \mathrm{C}\right)$ and thermophilic $\left(55^{\circ} \mathrm{C}\right)$ conditions were found to be capable of decolorizing 100 , 200 and 300 ppm of three types of azo dyes: Reactive Green 19 (45.56\%, 69.73\%; 63\%, 73.49\%; 70.02\%, 75.92\%), Reactive Orange 16 (46.08\%, 78.4\%; 64.21\%, 85.52\%; 74.95\%, 85.91\%) and Reactive Red 120 (29.11\%, 85.32\%; 63.35\%, 87.69\%; 72.02\%, 89.5\%) respectively after 7 days incubation time. Statistical analysis also showed that the anaerobic thermophilic conditions had significantly accelerated the decolorization process. The anaerobic thermophilic environment will be a good factor to include in future textile wastewater treatment plants.
\end{abstract}

Keywords: Anaerobic, Continuous Stirred Tank Reactor, Digested Sludge, Azo Dye, Thermotolerant

*Correspondence: fazilah@umt.edu.my; (Received: January 17, 2021 accepted: March 24, 2021)

Citation: Latif MAS, Ariffin F, Rudiyanto, et al. Decolorization of Synthetic Azo Dyes under Anaerobic Condition in a Continuous Stirred Tank Reactor, J Pure Appl Microbiol., 2021;15(2):658-666. doi: 10.22207/JPAM.15.2.10

(C) The Author(s) 2021 Open Access. This article is distributed under the terms of the Creative Commons Attribution 4.0 International License which permits unrestricted use, sharing, distribution, and reproduction in any medium, provided you give appropriate credit to the original author(s) and the source, provide a link to the Creative Commons license, and indicate if changes were made. 


\section{INTRODUCTION}

The batik (traditional wax-resist dyeing applied to whole cloth) industry especially in the Malaysian states of Kelantan and Terengganu is one of the main attractions in their tourism sector. Many small-scale factories were built years ago without proper waste management systems in place $^{1}$. Lack of awareness and proactive action towards textile wastewater may cause significant problems to the environment, mostly near rivers and the sea. Textile wastewater could be mutagenic, carcinogenic and very toxic towards aquatic life $^{2-4}$. There are significant problems arising from the textile industry, including their effluents that contain toxic metals like silicate and high levels of chemical oxygen demand $(C O D)^{5}$. Furthermore, dye effluent are highly colored, toxic and recalcitrant in nature textile industry had become the source of highly colored wastewater, which harms the marine life due to low sunlight penetration and excessive oxygen demand $d^{6}$. However, textile wastewater could be treated with various methods, including physically, chemically, and biologically or combinations of those methods.

The biological method seems to be the unconventional approach but could be a cost-effective and more eco-friendly way ${ }^{7}$. In the biological methods, many researchers use microbes such as fungi and bacteria that have the ability to decolorize azo dye by synthesizing specific enzymes for azo dye degradation. Laccase was known as one of the enzyme that used to degrade azo dye beside azoreductase and NADHDCIP reductase ${ }^{8}$. The action of laccase during degradation of azo bond was proved to be through nonspecific oxidation mechanism instead of azo bond cleavage ${ }^{9}$. Immobilized enzyme treatment is the most current trend in dye removal ${ }^{10}$. The mechanism of binding between dyes and enzymes had been tweaked to enhance the degradation efficiency ${ }^{11}$. Based on previous research, the anaerobic condition was found to be the best condition for azo dye decolorization where the mechanisms of azo compound reduction are wellknown ${ }^{2}$. A wide range of facultative and strictly anaerobic species of microbes have an excellent ability to decolorize azo dyes. Facultative anaerobic bacteria (Streptococcus faecalis, Proteus vulgaris) and strictly anaerobic bacteria (Eubacterium sp.; Bacteroides sp.;Clostridium sp.) are some examples of azo dye bioreduction microbes ${ }^{12}$.

Azo dye degradation under aerobic and anaerobic conditions gives different by-products due to several reasons. The possibility of bioaccumulative products during the anaerobic degradation process could be a problem but the main problem from aerobic systems could be in terms of energy and cost ${ }^{13}$. Aerobic systems could work best if anaerobic systems are also in some part of the full degradation. A study conducted by ${ }^{14}$ showed that degradation of RR2 dye in an anaerobic thermophilic condition produced recalcitrant aromatic amines, but this problem could be solved by further aerobic processes.

\section{MATERIALS AND METHODS Digested sludge sampling}

Digested sludge collected from a biogas reactor effluent at Serting Hilir Palm Oil Mill, Negeri Sembilan, Malaysia was stored in a freezer at $0^{\circ} \mathrm{C}$ until further use. Raw digested sludge was also analyzed for its chemical and physical characteristics. Total solid (TS), volatile solid (VS), $\mathrm{pH}$, and chemical oxygen demand (COD) were recorded. Specific methanogenic activity (SMA) activity was calculated in terms of gram COD consumed per gram of volatile solids per day (gCOD.gVS.d) and was performed in a labscale reactor. The SMA data could show the activity of acetoclastic methanogens, which are believed to be inside the mixed culture of digested sludge. Acetoclastic methanogens directly consume acetate as a carbon source and also directly produce methane gas as the end product. The gas produced from SMA test was analyzed using gas chromatography.

\section{Digested sludge acclimatization}

In order to test degradation in thermophilic and mesophilic conditions, the sludge has to acclimatize in separate labscale continuous stirred tank reactors (CSTR) for about one month. Circular water baths were used to control the temperature in the reactors. Hotplate stirrers were used to mix the sludge in the reactor continuously. A small opening at the top of the reactor was designed for overflow of the sludge, gas and for the purpose of feeding. The CSTR reactor was monitored every 
day and the temperature rose gradually until the thermophilic condition was achieved.

\section{Chemicals preparation}

The azo dyes used in this study namely, Reactive Green 19 (RG19) ( $\lambda \max , 624 \mathrm{~nm})$; Reactive Orange 16 (RO16) ( $\lambda \max , 493 \mathrm{~nm})$; and Reactive Red 120 (RR120) ( $\lambda \max , 534 \mathrm{~nm}$ ) were prepared in liquid form at the following concentrations which were 100 ppm, 200 ppm, and 300 ppm ${ }^{15}$. Each dye with respective concentrations was prepared in $1 \mathrm{~L}$. All bottles containing dyes were stored at room temperature. Minimum salt media (MSM) consisted of micronutrients, macronutrients and phosphate buffer. The micronutrients component consisted of $2 \mathrm{~g} / \mathrm{L}$ iron (III) chloride tetrahydrate $\left(\mathrm{FeCl}_{3} .4 \mathrm{H}_{2} \mathrm{O}\right), 2 \mathrm{~g} / \mathrm{L}$ cobalt (II) chloride hexahydrate $\left(\mathrm{CoCl}_{2} .6 \mathrm{H}_{2} \mathrm{O}\right), 0.5 \mathrm{~g} / \mathrm{L}$ manganese (II) chloride tetrahydrate $\left(\mathrm{MnCl}_{2} \cdot 4 \mathrm{H}_{2} \mathrm{O}\right), 30 \mathrm{mg} / \mathrm{L}$ copper(II) chloride dehydrate $\left(\mathrm{CuCl}_{2} \cdot 2 \mathrm{H}_{2} \mathrm{O}\right), 50 \mathrm{mg} / \mathrm{L}$ zinc chloride $\left(\mathrm{ZnCl}_{2}\right), 50 \mathrm{mg} / \mathrm{L}$ boric acid $\left(\mathrm{HBO}_{3}\right)$, $90 \mathrm{mg} / \mathrm{L}$ ammonium molybdate tetrahydrate $\left(\left(\mathrm{NH}_{4}\right) 4 \mathrm{Mo}_{7} \mathrm{O}_{2} \cdot 4 \mathrm{H}_{2} \mathrm{O}\right), 100 \mathrm{mg} / \mathrm{L}$ sodium selenite pentahydrate $\left(\mathrm{Na}_{2} \mathrm{SeO}_{3} .5 \mathrm{H}_{2} \mathrm{O}\right), 50 \mathrm{mg} / \mathrm{L}$ nickel (II) chloride hexahydrate $\left(\mathrm{NiCl}_{2} \cdot 6 \mathrm{H}_{2} \mathrm{O}\right), 1 \mathrm{~g} / \mathrm{L}$ ethylenediaminetetraacetic acid (EDTA), $1 \mathrm{ml} / \mathrm{L}$ hydrochloric acid $(\mathrm{HCl}) 36 \%, 0.5 \mathrm{~g} / \mathrm{L}$, resazurine, and $2 \mathrm{~g} / \mathrm{L}$ yeast extract. The macronutrient component consisted of $170 \mathrm{~g} / \mathrm{L}$ ammonium chloride $\left(\mathrm{NH}_{4} \mathrm{Cl}\right), 8 \mathrm{~g} / \mathrm{L}$ calcium chloride dehydrate $\left(\mathrm{CaCl}_{2} \cdot 2 \mathrm{H}_{2} \mathrm{O}\right)$, and $9 \mathrm{~g} / \mathrm{L}$ magnesium sulfate heptahydrate $\left(\mathrm{MgSO}_{4} \cdot 7 \mathrm{H}_{2} \mathrm{O}\right)$. Both micronutrients and macronutrients were prepared in $1 \mathrm{~L}$. Sodium acetate trihydrate $\left(\mathrm{Na}_{2} \mathrm{C}_{2} \mathrm{H}_{3} \mathrm{O}_{2} \cdot 3 \mathrm{H}_{2} \mathrm{O}\right)$ was prepared in $1 \mathrm{~L}$ as carbon source for future degradation analysis.

Decolorization of azo dye by using digested sludge

The biodecolorization process was conducted in small-scale reactors, made from serum bottles $125 \mathrm{ml}$ in volume. The fully sealed batch reactor design is suitable for anaerobic processes. Seventy percent of space of each serum bottle was used for the degradation process while $30 \%$ functioned as headspace for gases produced during the biodegradation. Three types of azo dyes namely, Reactive Green 19 (RG19) ( $\lambda$ max,624 $\mathrm{nm})$; Reactive Orange 16 (RO16) ( $\lambda \max , 493 \mathrm{~nm})$; and Reactive Red 120 (RR120) ( $\lambda \max , 534 \mathrm{~nm})$ at the following concentrations, 100 ppm, 200 ppm and $300 \mathrm{ppm}$ were tested with the digested sludge in the reactors ${ }^{15}$. The compositions of digested sludge, MSM and carbon source, sodium acetate trihydrate $\left(\mathrm{Na}_{2} \mathrm{C}_{2} \mathrm{H}_{3} \mathrm{O}_{2} \cdot 3 \mathrm{H}_{2} \mathrm{O}\right)$ in each serum bottle were calculated using following expression (1):

$$
\begin{aligned}
& \frac{\text { Vsub } \times \text { CODsub }}{\text { Vsludge } \times \text { VS sludge }}=0.5 \\
& V \text { sub }+ \text { V sludge }=0.0875 \\
& \text { A digested sludge to substrate ratio of } 2: 1
\end{aligned}
$$
was used in each reactor, with $87.5 \mathrm{ml}$ of bottle volume being used for the degradation process between digested sludge and substrate. Digested sludge and substrate were pipetted into the serum bottles using a micropipette. After reaching 70\% of the serum bottles' volume, the headspace was flushed with purified nitrogen gas for about 1.5 minutes to remove any dissolved oxygen inside the reactor. The narrowed bottle mouth was then sealed with a rubber stopper and aluminum crimp. Each type of sample was tested in triplicates plus one control sample that contained only MSM and azo dyes with no digested sludge. These batch reactors were then incubated in an incubator shaker for seven days or 168 hours. The incubation was performed at $35^{\circ} \mathrm{C}$ and $200 \mathrm{rpm}$. Another set of identical batch reactors was also prepared and incubated under the same conditions but with at a higher thermophilic temperature of $55^{\circ} \mathrm{C}$.

\section{Experimental data analysis of decolorization capacity}

After 168 hours of incubation process, the spent medium was centrifuged at $5000 \mathrm{rpm}$ for 10 minutes. The supernatant was measured for absorbance using a UV-Vis Spectrophotometer (UV1800) (Shimadzu, Japan). The measurement was based on specific wavelength of dye which were Reactive Green 19 (RG19) ( $\lambda \max , 624 \mathrm{~nm})$; Reactive Orange 16 (RO16) ( $\lambda \max , 493 \mathrm{~nm})$; and Reactive Red 120 (RR120) ( $\lambda \max , 534 \mathrm{~nm}$ ). The range of measurement was between 200 and 800 $\mathrm{nm}$. For statistical calculation, the decolorization capacity (\%) was calculated using following formula $(2)^{16}$ :

Decolorization capacity $(\%)=\frac{\text { Initial Abs-Final Abs }}{\text { Initial Abs }} \times 100$

Experimental data was analyzed using Response-Surface analysis $\mathrm{v} 2.10 .2^{17}$ and fitted to second order multiple regression models. The multiple linear regression equation model 
equation can be expressed as (3): $Y=\beta_{0}+\beta_{1} x 1+\beta_{2} x_{2}+\beta_{3} x_{1} x_{2}+\beta_{4} x_{1}^{2}+\beta_{5} x_{2}^{2} \ldots . .$. (3) where $Y$ is the response (decolorization capacity), $\beta_{0}$ the constant coefficient, $\beta_{1}, \beta_{2}$ were the coefficient of designated variables, $\beta_{3}$ the interaction coefficient and $\beta_{4}, \beta_{5}$ the quadratic coefficient, and $x_{1}, x_{2}$ were the variables coded.

\section{RESULTS AND DISCUSSION}

\section{Digested sludge characteristics profile}

Physical and chemical analyses of raw digested sludge were performed to show the relationship with the biodegradation process. Total solids (TS) showed the actual solid content in wet sludge, while volatile solids (VS) showed the amount of solids that could transform into the gaseous state without first being in liquid state. The $\mathrm{pH}$ of digested sludge is also an important factor as it might affect the degradation process. As shown in Table 1 the SMA test indicated the activity of methanogen microbes in the digested sludge that actively consumed the artificial substrate to form methane gas. The addition of acetate during the SMA test also showed the presence of acetoclastic methanogens within the digested sludge as methane production was detected as shown in Table 2. Acetoclastic methanogen bacteria were the thermophile microbes that could metabolize acetate to methane gas ${ }^{13}$. Methanosarcina sp. was a well-known species, viable and dominant

Table 1. Characteristics of digested sludge used (Average values of triplicates)

\begin{tabular}{ll}
\hline Parameter & Value \\
\hline Total Solid (TS) & $0.28 \%$ \\
Volatile Solid (VS) & $65 \%$ \\
Chemical Oxygen & $74.4149 \mathrm{~g} / \mathrm{L}$ \\
Demand (COD) & \\
pH & 7.40 \\
Specific Methanogenic & 0.0235 gCOD/gVS.day \\
Activity (SMA) & \\
\hline
\end{tabular}

Table 2. Composition of gases produced after the SMA test (Average value of triplicates)

\begin{tabular}{lc}
\hline Type of gas & Composition (\%) \\
\hline Methane gas $\left(\mathrm{CH}_{4}\right)$ & 59.14 \\
Carbon dioxide $\left(\mathrm{CO}_{2}\right)$ & 40.84
\end{tabular}

in anaerobic digesters, that could tolerate a wide range of $\mathrm{pH}$ (6-7), and highly dependent on acetate concentration ${ }^{18}$. Since the reactor in the present study used sodium acetate trihydrate as the carbon source, this type of acetoclastic methanogen is proposed to be the predominant biodegradation microorganism.

\section{Regression model equation development}

The coefficient of the response function (Eq. 3), the $t$ and $p$-values for decolorization capacity were obtained using experimental data and presented in Table 3. By using experimental data, the following second order multiple regressions was fitted to the decolorization capacity results and expressed in terms of coded factors according to type of azo dye tested:

$$
\begin{aligned}
& Y=68.24+6.76 x_{1}+7.66 x_{2}-4.57 x_{1} x_{2}-2.93 x_{2}^{2} \\
& Y=75.52+16.34 x_{1}+11.77 x_{2}-9.68 x_{1} x_{2}-6.53 x_{2}^{2} \\
& Y=74.86+10.77 x_{1}+9.10 x_{2}-5.34 x_{1} x_{2}-3.53 x_{2}^{2}
\end{aligned}
$$

In Table 3, the coded variable $x_{1}$ represent temperature factor and $x_{2}$ represent concentration factor. Based on observation, the coefficient for both factors and the interaction $(P<0.000$ for all) were highly significant. The coefficients of determination $\left(R^{2}\right)$ for the predicting equations were $93 \%, 97 \%$ and $99 \%$ respectively. In addition, the root means square error (RMSE) for those azo dyes was close to 0 . Hence, the equation could be used in predicting the response with the combined value of factors.

Decolorization of azo dyes using digested sludge Based on contour plot in Fig. 1, showed the decolorization capacity of three types of azo dye. The plot in Fig. 1 (b) showed the highest value of decolorization capacity at $90 \%$ situated at high concentration and also high temperature. All three plots showed the same pattern as the equation (4), (5), (6) show the same synergistic effect with positive sign in front. Fig. 1 (b) show the most sensitive decolorization result even with small alteration in concentration or temperature factors. The diagram also showed that the decolorization percentages were significantly higher in reactors incubated under the thermophilic condition $\left(55^{\circ} \mathrm{C}\right)$ for all of the tested reactive dyes (RG19, RO16 and RR120). Moreover, the decolorization percentages differ between the three dyes, suggesting that their molecular structures must have an important effect on their decolorization rate. However, there 

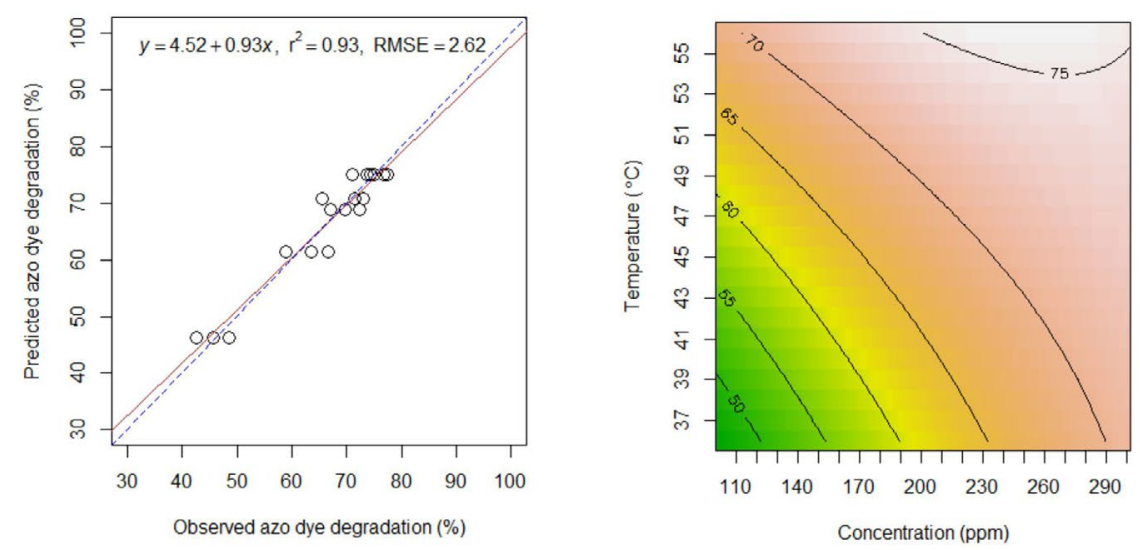

(a)
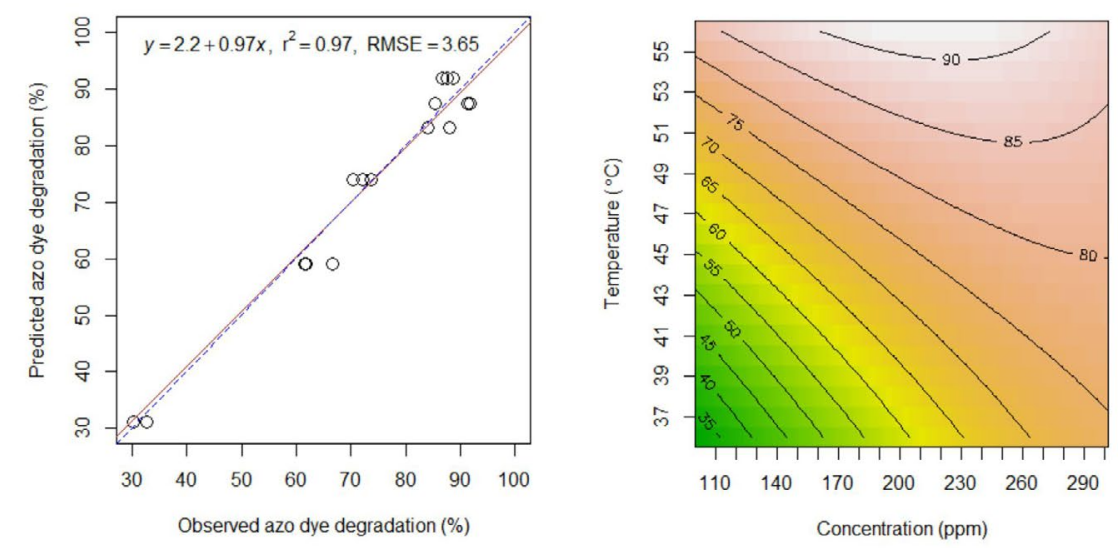

(b)
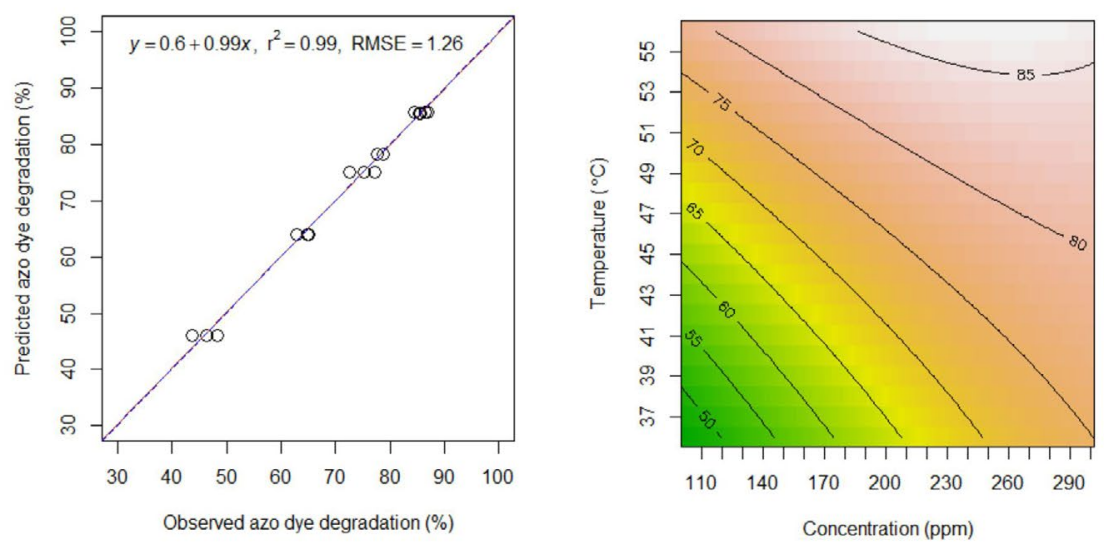

(c)

Fig. 1 Scatter plots for the observed and predicted value of azo dye degradation and corresponding contour plots for azo dyes decolorization capacity with interaction between concentration and temperature factors. (a) Reactive Green 19 (RG19); (b) Reactive Red 120 (RR120); (c) Reactive Orange 16 (RO16). 
was no significant difference between $200 \mathrm{ppm}$ and 300 ppm samples of RO 16 at $55^{\circ} \mathrm{C}$ and similarly for RR120 and RG19. The highest decolorization capacity was at $89.5 \pm 3.54 \%$ for the $300 \mathrm{ppm}$ RR120 sample that was incubated at $55^{\circ} \mathrm{C}$. A previous study ${ }^{19}$, showed $78.6 \%$ decolorization of RO3R which is similar in molecular weight to RO16, but the incubation condition was mesophilic and the time frame was 24 hours only.

The concentration of reactive azo dyes could be a factor in the decolorization process, but the results only showed significant differences under the mesophilic condition $\left(35^{\circ} \mathrm{C}\right)$. The initial absorbance ranges for 100, 200 and 300

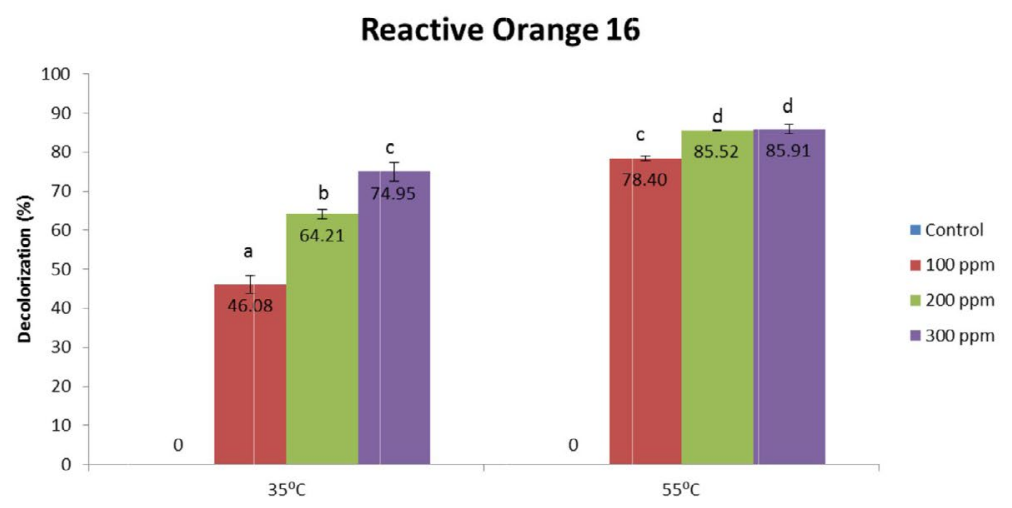

\section{Reactive Green 19}
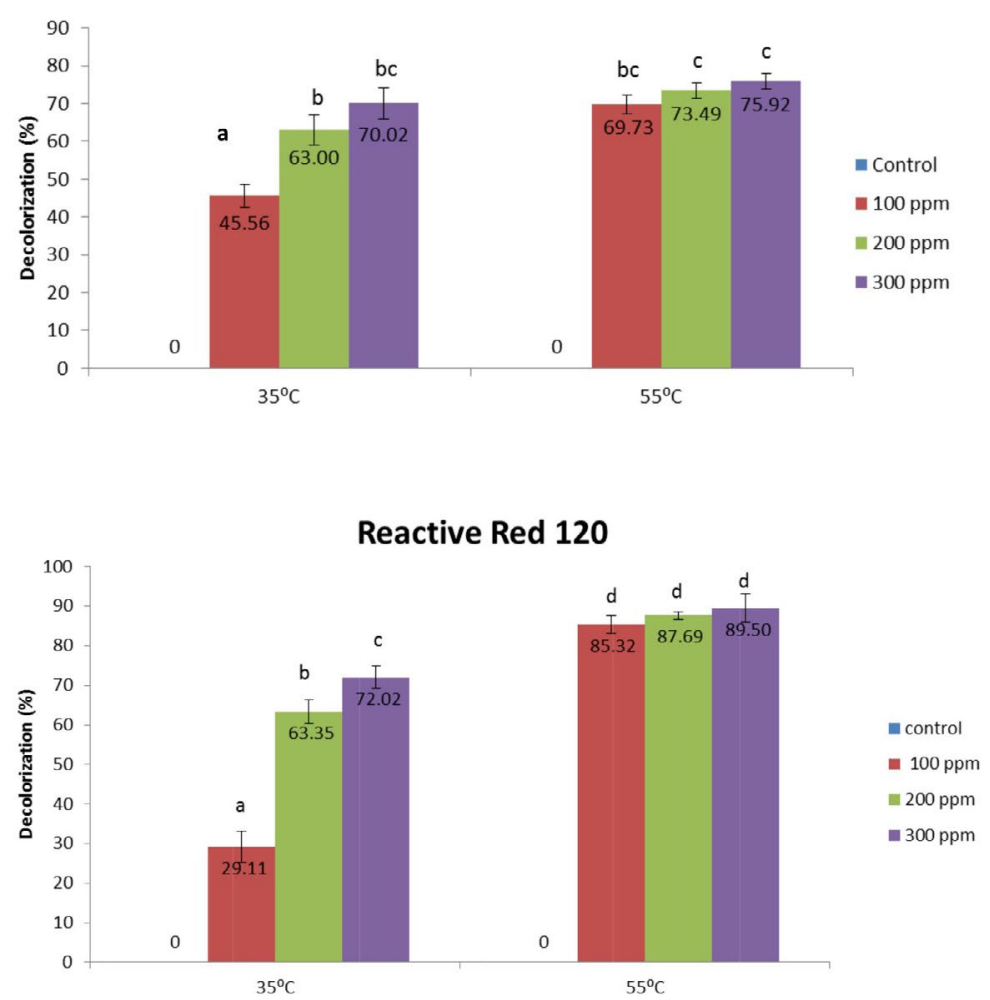

Fig. 2. Decolorization capacity of three types of azo dyes at $35^{\circ} \mathrm{C}$ and $55^{\circ} \mathrm{C}$ after 7 days incubation. The data show the mean \pm standard deviation of triplicates. Mean data accompanied by different letters indicate significant difference within each respective group (Tukey's HSD test, $p<0.05$ ). 
Latif et al. | J Pure Appl Microbiol | 15(2):658-666 | June 2021 | https://doi.org/10.22207/JPAM.15.2.10

Table 3. Estimated regression coefficients for decolorization capacity (\%) in coded units

\begin{tabular}{|c|c|c|c|c|}
\hline Term & Estimate & Std. error & $\mathrm{t}$ value & $\operatorname{Pr}(>|t|)$ \\
\hline \multicolumn{5}{|c|}{ Reactive Green 19} \\
\hline Intercept & 68.24 & 1.30 & 52.37 & $<2 \mathrm{e}-16$ \\
\hline$x_{1}$ & 6.76 & 0.75 & 8.99 & $6.13 \mathrm{E}-07$ \\
\hline$x_{2}$ & 7.66 & 0.92 & 8.31 & $1.46 \mathrm{E}-06$ \\
\hline$x_{1}^{2} x_{2}$ & -4.57 & 0.92 & -4.96 & 0.000263 \\
\hline$x_{1}^{2}$ & NA & NA & NA & NA \\
\hline$x_{2}^{1}$ & -2.93 & 1.60 & -1.84 & 0.089116 \\
\hline \multicolumn{5}{|c|}{ Reactive Red 120} \\
\hline Intercept & 75.52 & 1.78 & 42.38 & $2.54 \mathrm{E}-15$ \\
\hline$x_{1}$ & 16.34 & 1.03 & 15.88 & $6.81 \mathrm{E}-10$ \\
\hline$x_{2}^{1}$ & 11.77 & 1.26 & 9.34 & 3.93E-07 \\
\hline$x_{1}^{2} x_{2}$ & -9.68 & 1.26 & -7.68 & $3.47 \mathrm{E}-06$ \\
\hline$x_{1}^{2}$ & NA & NA & NA & NA \\
\hline$x_{2}^{2}$ & -6.53 & 2.18 & -2.99 & 0.0104 \\
\hline \multicolumn{5}{|c|}{ Reactive Orange 16} \\
\hline Intercept & 74.86 & 0.61 & 123.04 & $<2 \mathrm{e}-16$ \\
\hline$x_{1}$ & 10.77 & 0.35 & 30.65 & $1.65 \mathrm{E}-13$ \\
\hline$x_{2}$ & 9.10 & 0.43 & 21.14 & $1.88 \mathrm{E}-11$ \\
\hline$x_{1}^{2} x^{2}$ & -5.34 & 0.43 & -12.41 & $1.40 \mathrm{E}-08$ \\
\hline$x_{1}^{1}$ & NA & NA & NA & NA \\
\hline$x_{2}^{2}$ & -3.53 & 0.75 & -4.74 & 0.00039 \\
\hline
\end{tabular}

ppm of the tested azo dyes were wide enough to show the any inhibition or effectiveness of decolorization. Subsequently, the rate of reaction, or the decolorization capacity of the reactive azo dyes incubated at $35^{\circ} \mathrm{C}$, generally showed significant increment as the concentration increased from 100 to 300 ppm for the RO16 and RR120 dyes, though RG19 showed no significant difference between 200 and 300 ppm. The situation was the opposite for the dyes tested under the thermophilic condition $\left(55^{\circ} \mathrm{C}\right)$. No significant difference was observed between all of the different concentrations of RG19 and RR120, though for RO16, there was significant difference between 100 ppm and 200 ppm but no significant difference between 200 ppm and 300 ppm.

A previous study showed a decrease in the rate of reaction after an increase in dye concentration ${ }^{20}$. One of the suggested reasons for this situation was whether the composition of digested sludge in the labscale reactor was of enough quantity to decolorize $300 \mathrm{ppm}$ and above. Furthermore, the $300 \mathrm{ppm}$ samples also resulted in higher decolorization capacity than two other lower concentrations. From this finding, there is a possibility of inhibition occurring due to too much digested sludge composition affecting the dye decolorization. The ratio of cells to dye might be too low and blockage of active sites of dyes would affect the bioprocess ${ }^{2}$. In the present study, the best decolorization percentage was produced by 300 ppm dyes, but the optimal concentration for decolorization was not confirmed. As the total solids (TS) of the digested sludge was under $1 \%$, there were many substances that could act as possible inhibitors and for other processes to occur at the same time. For instance, the phenol-degrading sludge that had large particle size showed higher degradation rate, but the small particle size showed the best methanogenic activity with the aid of substrates. The larger size of sludge particle was favorable for hydrogenotrophic methanogen and syntrophic bacteria, but less acetoclastic methanogens ${ }^{21}$.

The biodegradation process in anaerobic digestion is performed in several steps, starting from hydrolysis, acidogenesis, acetogenesis and lastly methanogenesis ${ }^{22,23}$. The hydrolysis step is dependent on temperature and several studies showed the process works best under thermophilic 
conditions. The next stage, acidogenesis is $\mathrm{pH}$ dependent, which works best at an optimum $\mathrm{pH}$ of 6.0 and temperatures between 34 and $36^{\circ} \mathrm{C}^{24,25}$. The next stages of acetogenesis and methanogenesis also depend on temperature as found by Kiyohara et al., ${ }^{26}$. Their observations showed that acetogenesis and methanogenesis worked about 1.8 and 1.6 times faster, respectively under a thermophilic condition $\left(55^{\circ} \mathrm{C}\right)$ rather than a mesophilic condition $\left(35^{\circ} \mathrm{C}\right)$.

\section{CONCLUSION}

Thermotolerant digested sludge containing undetermined microbes were able to degrade and decolorize synthetic reactive azo dyes (RG19, RO16 and RR120). The thermophilic condition $\left(55^{\circ} \mathrm{C}\right)$ was shown to significantly accelerate the decolorization process compared to the mesophilic condition $\left(35^{\circ} \mathrm{C}\right)$ due to effectiveness of anaerobic digestion. The decolorization capacity reached $89 \%$, which showed the potential use of acclimatized digested sludge in dye biodegradation. Microbial shifting from mesophilic to thermophilic condition might be the viewpoint for the increment in terms of the degradation process. Specific microbes had delivered an assist by synthesizing enzymes and react with the dye molecules to become simpler compounds and metabolites. Consequently, the uncertainty in industrial textile effluent could bring this method useful and worth being implemented in near future.

\section{ACKNOWLEDGMENTS}

The authors fully acknowledge the Ministry of Higher Education, Malaysia which made this important study viable and effective. We would like to thank the Faculty of Science and Marine Environment and Universiti Malaysia Terengganu (UMT) for research facilities and support.

\section{CONFLICT OF INTEREST}

The authors declare that there is no conflict of interest.

\section{AUTHORS' CONTRIBUTION}

All authors listed have made a substantial, direct and intellectual contribution to the work, and approved it for publication.

\section{FUNDING}

This study was supported by the Ministry of Higher Education, Malaysia for funding this work under the Fundamental Research Grant Scheme (FRGS 59519) Grant No. FRGS/1/2018/STG05/ UMT/02/3.

\section{DATA AVAILABILITY}

All datasets generated or analyzed during this study are included in the manuscript.

\section{ETHICS STATEMENT}

This article does not contain any studies with human participants or animals performed by any of the authors

\section{REFERENCES}

1. Akhir NHM, Ismail NW, Utit C. Malaysian batik industry contribution analysis using direct and indirect effects of input-output techniques. Int J Bus Soc. 2018;19(1):181194.

2. Jamee $R$, Siddique R. Biodegradation of synthetic dyes of textile effluent by microorganisms: an environmentally and economically sustainable approach. Eur J Microbiol Immunol. 2019;9(4):114118. doi: 10.1556/1886.2019.00018

3. Bilal M, Asgher M, Parra-Saldivar R, et al. Immobilized ligninolytic enzymes: An innovative and environmental responsive technology to tackle dye-based industrial pollutants - A review. Sci Total Environ. 2017;576:646659. doi: 10.1016/j.scitotenv.2016.10.137

4. Rasheed T, Bilal M, Nabeel F, Adeel M, Iqbal HMN. Environmentally-related contaminants of high concern: Potential sources and analytical modalities for detection, quantification, and treatment. Environ Int. 2019;122:52-66. doi: 10.1016/j.envint.2018.11.038

5. Birgani PM, Ranjbar N, Abdullah RC, et al. An efficient and economical treatment for batik textile wastewater containing high levels of silicate and organic pollutants using a sequential process of acidification, magnesium oxide, and palm shell-based activated carbon application. J Environ Manage. 2016;184(2):229-239. doi: 10.1016/j.jenvman.2016.09.066

6. Holkar CR, Jadhav AJ, Pinjari D V., Mahamuni NM, Pandit AB. A critical review on textile wastewater treatments: Possible approaches. J Environ Manage. 2016;182:351366. doi: 10.1016/j.jenvman.2016.07.090

7. Rashidi HR, Sulaiman NMN, Hashim NA. Batik Industry Synthetic Wastewater Treatment Using Nanofiltration Membrane. Procedia Eng. 2012;44:2010-2012. doi: 10.1016/j.proeng.2012.09.025

8. Liu W, Liu C, Liu L, et al. Simultaneous decolorization of sulfonated azo dyes and reduction of hexavalent chromium under high salt condition by a newly isolated salt-tolerant strain Bacillus circulans BWL1061. Ecotoxicol Environ Saf. 2017;141:9-16. doi: 10.1016/j. ecoenv.2017.03.005

9. Guo G, Li X, Tian F, et al. Azo dye decolorization by 
a halotolerant consortium under microaerophilic conditions. Chemosphere. 2020;244:125510. doi: 10.1016/j.chemosphere.2019.125510

10. Bilal M, Ashraf SS, Iqbal HMN. Laccase-Mediated Bioremediation of Dye-Based Hazardous Pollutants. In: Methods for Bioremediation of Water and Wastewater Pollution. Springer. 2020:137-160.

11. Jun LY, Yon LS, Mubarak NM, et al. An overview of immobilized enzyme technologies for dye and phenolic removal from wastewater. J Environ Chem Eng. 2019;7(2):102961. doi: 10.1016/j.jece.2019.102961

12. Sarkar S, Banerjee A, Halder U, Biswas R, Bandopadhyay R. Degradation of Synthetic Azo Dyes of Textile Industry: a Sustainable Approach Using Microbial Enzymes. Water Conserv Sci Eng. 2017;2(4):121-131. doi: 10.1007/s41101-017-0031-5

13. Khan MZ, Singh S, Sreekrishnan TR, Ahammad SZ. Feasibility study on anaerobic biodegradation of azo dye reactive orange 16. RSC Adv. 2014;4(87):4685146859. doi: 10.1039/c4ra06716a

14. Hu X, Gao H, Zhang Y, Zhou YX, Jiang JY. Study on biodegradation of azo dye by thermophilic anaerobic process. In: 3rd International Conference on Bioinformatics and Biomedical Engineering, ICBBE 2009; Beijing, China.

15. Saratale RG, Saratale GD, Chang JS, Govindwar SP. Bacterial decolorization and degradation of azo dyes: A review. J Taiwan Inst Chem Eng. 2011;42(1):138-157. doi: 10.1016/j.jtice.2010.06.006

16. Ajaz M, Rehman A, Khan Z, Nisar MA, Hussain S. Degradation of azo dyes by Alcaligenes aquatilis $3 \mathrm{c}$ and its potential use in the wastewater treatment. $A M B$ Express. 2019;9:64. doi: 10.1186/s13568-019-0788-3

17. Lenth RV. Response-surface methods in R, using RSM. J Stat Softw. 2010;32(7):1-17. doi: 10.18637/jss.v032. i07
18. Nnaji CC. A review of the upflow anaerobic sludge blanket reactor. Desalin Water Treat. 2014;52(2224):4122-4143. doi: 10.1080/19443994.2013.800809

19. Bras R, Isabel M, Pinheiro HM, Goncalves IC. Batch tests for assessing decolourisation of azo dyes by methanogenic and mixed cultures. Journal of Biotechnology. 2001;89(2-3):155-162. doi: 10.1016/ S0168-1656(01)00312-1

20. Sponza DT, Isik M. Decolorization and inhibition kinetic of Direct Black 38 azo dye with granulated anaerobic sludge. Enzyme Microb Technol. 2004;34(2):147-158. doi: 10.1016/j.enzmictec.2003.10.006

21. Wang J, Wu B, Sierra JM, He C, Hu Z, Wang W. Influence of particle size distribution on anaerobic degradation of phenol and analysis of methanogenic microbial community. Environ Sci Pollut Res. 2020;27(10):1039110403. doi: 10.1007/s11356-020-07665-z

22. Ohimain El, Izah SC. A review of biogas production from palm oil mill effluents using different configurations of bioreactors. Renew Sustain Energy Rev. 2017;70:242253. doi: 10.1016/j.rser.2016.11.221

23. Manchala KR, Sun Y, Zhang D, Wang Z-W. Anaerobic Digestion Modelling. Adv Bioenergy. 2017;2:69-141. doi: 10.1016/bs.aibe.2017.01.001

24. Ince O. Performance of a two-phase anaerobic digestion system when treating dairy wastewater. Water Res. 1998;32(9):2707-2713. doi: 10.1016/ S0043-1354(98)00036-0

25. Dichtl N. Thermophilic and mesophilic (two-stage) anaerobic digestion. Water Environ J. 1997;11(2):98104. doi: 10.1111/j.1747-6593.1997.tb00098.x

26. Kiyohara $Y$, Miyahara T, Mizuno O, Noike T, Ono K. A comparative study of thermophilic and mesophilic sludge digestion. Water and Environment Journal. 2000;14(2):150-154. doi: 10.1111/j.1747-6593.2000. tb00242.x 